\section{DIFERENÇAS ULTRA-ESTRUTURAIS ENTRE AS CElULAS DE LEYDIG DE CAVALO, JUMENTO E SEU HIBBRIDO}

\author{
FERNANDA DA CRUZ LANDIM E ALVARENGA \\ Professor Assistente
}

Faculdade de Medicina Veterinária e Zootecnia da UNESP

Campus de Botucatu

ALVARENGA, F.C.L. Diferenças ultra-estruturais entre as colulas de Loydig de cavalo, jumento e seu híbrido. Brax. J. vet Res. anlm. Scl., Sảo Paulo, v.29, n.2, p.173-80, 1992.

RESUMO: A ultra-estrutura das cólulas de Loydig de cavalos, jumentos $\theta$ burros foi comparada com o intuito de se estudar as diferenças morfológicas existentes. Todas as colulas estudadas apresentam um retículo endoplasmático liso bem desenvolvido, característico das chlulas produtoras de hormónios esteróides. No cavalo, no entanto, esta organela aparentemente se apresenta mais abundante. As mitocondrias encontradas săo pequenas, redondas e numerosas. Nos jumentos e burros uma grande quantidade de microfilamentos aparece proximo ao núcleo. A funçăo destes filamentos ainda desconhecida pois parece năo existir razáo para a presença de um citoesqueleto tảo desenvolvido em cólulas intersticiais, imóveis e sem funçăo de sustentaçāo, exceto, talvez, a relaçăo com o transporte de substâncias precursoras de esteróides o/ou organelas intracelulares

UNITERMOS: CGlulas de Loydig, ultra-estrutura; Cavalos; Jumentos

\section{INTRODUÇẢO}

A regulaça da espermatogênese nos mamíteros é mediada por hormónios do hipotalarno, hipofise e tecido endocrino testicular. No testiculo, a secreçăo dos hormónios é realizada polas colulas intersticiais, também denominadas cólulas de Loydig. Estas colulas, sob o estimulo da gonadotrofina hipofiatria (HH), secretam andrbgenos que irão estimular o desenvolvimento dos gametas. Assim como as demais cólulas produtoras de hormónios esteróides, as celulas de Leydig apresentam um retículo endoplasmático liso (REL) muito desenvolvido e mitocondrias com cristas tubulares.

A ultra-estrutura das cólulas intersticiais tem sido descrita em diversos animais: homens (FAWCETT; BURGOS
5, 1960), ratos (LEESON 8,1963 ; MORI; CHRISTENSEN 10 , 1980), cobaias (CHRISTENSEN 4,1965 ), porcos (BELT. CAVAZOS 3 1967; LUNSTRA of al. 9 1986) e cavalos (GONZALEZ-ANGULO ot at. ${ }^{6}, 1975$; ALMAHBOBI ot al. ${ }^{2}$, 1988). Embora estas celulas possuam caracteristicas gerais comuns nas difarentes especies, podem diferir em alguns detalnes estruturais.

HERNANDEZ-JAUREGUI \& MARQUEZ MONTER 7

(1977) ao compararem a ultraestrutura do testiculo de cavalos, jumentos e burros constataram que embora o número de células de Leydig nos burros estivesse diminuído, estas apresentavam um aspecto semelhante ao de outras espécies; no entanto. tal trabalho atem-se basicamente as alteraçōes que ocorrem a nivel de células germinativas e não ao tecido intersticial.

Como as cólulas de Leydig tanto de jumento como de burros năo estảo descritas na literatura consultada, este trabalho tem por objetivo a realizaçāo de um estudo estrutural comparativo entre colulas de Leydig de cavalos. jumentos e burros.

\section{MATERLAL E MÉTODO}

O presente estudo foi realizado no laboratório de Microscopia Eletrónica do Instituto de Biociências da UNESP, campus de Botucatu.

Foram utilizados 4 burros (Equus asinus $X$ Equus caballus), 2 jumentos (Equus asinus) e 2 cavalos (Equus caballus), com idade entre 2,5 e 3 anos. Os animais foram submetidos a castraçảo e pequenos fragmentos de tecido testicular foram retirados e fixados em glutaraldeido $2.5 \%$. em tampåo cacodilato de sódio 0,1 M, a $4^{\circ} \mathrm{C}$. Após o tempo de fixaçăo o material foi lavado em mesmo tampão. A pósfixaçąo foi feita em tetróxido de ósmio a $1 \%$ no mesmo tampåo durante 3 horas à temperatura de $4{ }^{\circ} \mathrm{C}$. Após esse tempo, foi efetuada a lavagem por tress vezes em agua bidestilada. Procedeu-se entăo à desidrataçáo, a qual foi realizada en séries de acetona com concentraçóes crescentes $(30,50,70,90,100 \%)$ durante 5 minutos cada. A inclusão foi então realizada em Epon 812.

Os cortes ultrafinos foram obtidos com navalha de diamante e colnidos em grades de cobre, corados com acotato de uranila e cirrato de chumbo (REYNOLOS 11 , 1963) e examinados ao microscópio eletrónico de transmissăo, modelo Phillips EM 301.

As fotografias foram obtidas utilizando-se filme Eastman Kodak $35 \mathrm{~mm}$ 5302, revelado com D-19 e copiado em papel Kodabromide F2 ou F3.

\section{RESULTADOS E DISCUSSĀO}

As celulas de Leydig de cavalos, jumentos e burros apresentam núcleo arredondado, muitas vezes de contornos 


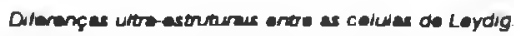

irregulares, com massas de heterocromatina distribuida irregularmente e nucléolos proeminentes.

No cavalo, o reticulo endoplasmático liso aparece extremamente desenvolvido (Fig. 1A) e constituido por pequenas vesiculas compactadas. distribuidas por todo o citoplasma, com exceçảo de áreas onde estảo presentes grupamentos de mitocôndrias (Fig. 1B). Estas mitocôndrias apresentam forma oval ou arredondada, matriz de média densidade eletrónica e cristas pouco numerosas. Agumas mitocondrias apresentam-se dilatadas o outras aparentemente em divisăo (Fig 1B - setas). $O$ reticulo endoplasmatico rugoso aparece em pequena quantidade, sendo constituído por perfis isolados de cisternas localizadas principalmente na regiāo perinuclear, enquanto polirribossomos livres apresentam-se espalhados por entre o retículo liso (Fig. 1A e 1B). O complexo de Golgi apresentase sob a forma de vários dictiossomos de tamanho reduzido espalhados pela célula (Fig. 1B). Na regiảo perinuclear observa-se pequena quantidade de microfilamentos disfribuidos irregularmente. Existe ainda no citoplasma, abundância de grãos de elevada electrodensidade, provavelmente estruturas de natureza lisossómica.

No caso dos jumentos as chlulas de Leydig apresentam características ultra-estruturais ligeiramente diferentes. O retículo endoplasmático liso, embora abundante, ocorre aparentemente em menor quantidade, constituido por estruturas tubulares dispersas pelo citoplasma (Fig. 2). Entre os túbulos do retículo endoplasmático liso săo vistas mitocóndrias pequenas de forma arredondada, matriz de elevada electrodensidade $\theta$ cristas mais abundantes. Aparentemente possuem um major número de mitocondrias quando comparadas as do cavalo, sendo que algumas das mitocondrias apresentam sinais de degeneraçăo (Fig. 2 - setas) caracterizados por figuras mielínicas em seu interior. Esta característica das mitocondrias 6 frequentemente observada em colulas produtoras de hormónios esterbides e parece ser devida ao desgaste que ocorre nestas organelas por estarem elas envolvidas diretamente na sintese de esteróides. Da mesma maneira, o grande número de mitocóndrias em divisão observado nos cavalos, assim como a morfologia vacuolizada destas, a qual 6 característica de organelas jovens, aparentemente está relacionado à reposição de tais organelas (ALBERTS ot al. 1, 1983). Assim, a diferença existente na morfologia das mitocondrias de cavalos 0 jumentos parece ser, simplesmente, devida a estarem estas células em diferentes fases de seu ciclo.

Na regiảo perinuclear das cólulas de Leydig de jumentos observa-se depósito de grande quantidade de microfilamentos, dispostos sem arranjo preferencial (Fig. 2). O complexo de Golgi, como no cavalo, bem evidente $\theta$ desenvolvido, sem no entanto assumir grandes dimensoes. No citoplasma das cólulas de jumento também são vistos grânulos de elevada densidade eletrónica provavelmente de natureza lisossómica (Fig. 2).
As cólulas de Leydig de burros apresentam características intermediárias quando comparadas . as espécies parentais. O reticulo endoplasmático liso, embora apresente um aspecto vesicular semelhante ao das células de cavalo, distribui-se pelo citoplasma de maneira semeltante à observada nos jumentos (Fig. 3B). As mitocondrias encontram-se distribuidas por entre o retículo endoplasmático liso, sảo pequenas, com matriz de elevada densidade eletrônica e cristas evidentes as quais eventualmente assumem um aspecto vesicular (Fig. 3 . setas). Em alguns casos estas organelas aparecem com um aspecto alongado (Fig. 3B). Como o material testicular utilizado foi coletado de diferentes animais em diversas epocas do ano e a morfologia das cólulas de Leydig se manteve constante, foi descartada a hipótese da diferente quantidade de reticulo endoplasmático liso estar ligada a atividade metabólica da célula, parecendo ser uma característica da espécie.

A quantidade de microfilamentos encontrada nas celulas de Leydig de burros é bern major que a presente nas celulas de cavalos, porém menor que a preeente em jumentos. Aparentemente a presença destea filamentos b responsável pela menor quantidade de reticulo endoplasmático liso observada nas cólulas de Loydig dos jumentos e burros, uma vez que estes ocupam boa parte do citoplasma. Freqüentemente os filamentos se dispoem sem arranjo preferencial (Fig. 3A • 3B), mas em pelo menos uma chlula estes se apresentam com arranjo concentrico (Fig. 4B). A quantidade e distribuiç̧̋o deste materia também varia de celula para cblula em um mesmo anima. Na majoria das colulas aparece em grandes quantidades. distrlbuido ao redor do núcleo (Fig. 3A), podendo, no entanto, se encontrar isolado em porçoes do citoplasma mais afastadas (Fig. 4B). Outras chlulas, entretanto, apresentam pequena quantidade deste material disposto ao redor do núcleo (Fig. 38 e 4A). O meamo tipo de estruturas filamentosas foi visto em chlulas de Sertoli, as quais têm em comum com as celulas de Leydig o contorno irregular do núcleo e a sintese de hormónios esteróides.

A função de tais filamentos nas células de Leydig 6 obscura, pois nảo existe razảo aparente para a presença de um citoesqueleto tão desenvolvido e evidente em cólulas intersticiais, imóveis e sem funçăo de sustentaçảo, exceto, taivez, a sua relaçăo com o transporte de precursores de esteróides e/ou organelas intracelulares.

Diferentemente das células de cavalo e de jumento, nas colulas de Leydig de burros encontram-se depósitos de material lipídico, possivelmente colesterol, os quais podem estar localizados no interior da massa de microfilamentos (Fig. 4B) ou esparsos pelo citoplasma (Fig. 3 e 4B). As gotas de lipídio apresentam electrodensidade media e com freqüência apresentam uma zona de baixa electrodensidade em seu interior (Fig. 3 e 4B). Este aspecto pode ser devido à presença de material lipidico de natureza diferente dentro da mesma gota, pois o lipidio apresenta maior 
electrodensidade quanto maior for a quantidade de ácidos graxos insaturados. Outra explicaçăo para as diferentes tonalidades do lipídio seria o processo de mobilizaçäo deste. sendo que neste caso é mais característico o aspecto lamelar dos bordos dos grânulos (Fig. 4A).

Nos burros, os grảnulos de origem lisossômica aparecem em menor quantidade quando comparado as espécies parentais. No entanto, a mobilização do lipídio pode contribuir para a formaçāo de residuos formando grânulos electrodensos, os quais sảo de natureza lisossômica. Estes grânulos podem também se originar devido à degeneração de material estocado que nảo foi totalmente digerido ou eliminado.

Desta maneira, a diferença quanto à quantidade e tipo de grânulos observados entre cavalos, jumentos e burros parece ser devida a diferenças quanto ao momento metabólico em que se encontra a célula.

As colulas de Leydig de burros, apesar de apresentarem pequenas diferenças quando comparadas às das espécies parentais, possuem um aspecto geral de celula esteroıdogénica normal, estando, portanto, aptas a desempenharem sua funçảo de produçăo hormonal.

ALVARENGA, F.C.L Ultrastructural differences between Loydig colls of horses: asses and hinnies. Braz. J. vet. Res. anim. Scl., Săo Paulo, v.29, n.2, p.173-80, 1992.

SUMMARY: The ultrastructure of Leydig cells of horses, asses and hinnies was compared to show the morphological differences among them. These cells have a well developed smooth endoplasmic reticulum, indicating a normal steroidogenic activity, but in the horse, this organelle seems to be a litje more abundant. The mitochondria was round, small and numerous. In asses and hinnies a great amount of microfilaments appear mainly near the nucclei. The function of these filaments is unknown, because there is no aparent reason for these cells to have a well developed cytoskeletal since they are imobile and don't have a supporting tunction, except, by, the steroids precursors and intracellular organelles transport.

UNITERMS: Leydig cells, ultrastructure; Horse; Donkey

\section{REFERENCLAS BIBUOGRAFICAS}

01-ALBERTS, B.; BRAY, D.; LEWIS, J.; RAFF, M.; ROBERTS, K.; WATDON, J.D. Molecular blology of the cell Garland Publishing, 1983. p.9, 259: The biogenesis of mitochondria and chloroplasts.
02-ALMAHBOBI, G.; PAPADOPOULOS, V.; CARREAU, $S$. SILBERZAHN, P. Age related morphological and functional changes in the Leydig cells of the horse. Biol. Reprod, v.38, p.653-65, 1988

03-BELT, W.D.; CAVAZOS, L.F. Fine structure of the interstitial cells of Leydig in the boar. Anat. Rec. v. 158, p. $333-50,1967$

O4-CHRISTENSEN, A.K. The fine structure of the testicular interstitial cells in guinea pigs. J. cell Biol., v.26, p.911-35, 1965.

05-FAWCETT, D.W.; BURGOS, M.H. Studies on the fine structure of the mammalian testis. II. The human interstitial tissue. Amer. J. Anat. v.107, p.245-69, 1960.

O6-GONZALEZ-ANGULO, A; HERNANDEZJAUREGUI, $P$. MARTINEZ-ZEDILO, G. Fine structure of the gonads of the horse and its functional implications. J. Reprod. Fertl., p.563-7, 1975. Supplement 23. /Apresentado ao $1^{8}$ International Symposium on Equine Reproduction, Cambridge, 1974/

07-HERNANDEZJAUUREGUI, P.; MAROUEZ MONTER, $H$. Fine structure of mule testis: ligh and electron microscopy study. Amer. J. vet Res., v.38, p.443-7, 1977.

O8-LEESON, C.R. Observations on the fine structure of rat interstitial tissue. Acta anat. (Basel), v.52, p.34-48, 1963.

OFLUNSTRA, D.D.; FORD, J.J.; CHRISTENSON, R.K.; ALLRCH, R.D. Changes in Leydig cell ultrastructure and function during pubertal development in the boar. Biol. Reprod., v.34, p.145-58, 1986

10-MORI, H.; CHRISTENSEN, A.K. Morphometric analysis of Leydig cells in the normal rat testis. J. cell. Biol., v.84, p.340-54, 1980.

11-REYNOLDS, E.S. The use of lead citrate at high pH as an electron-opaque stain in electron microscopy. J. cell Blof., v.17, p.208-13, 1963. Aprovado para publicaçāo em 21/05/92 


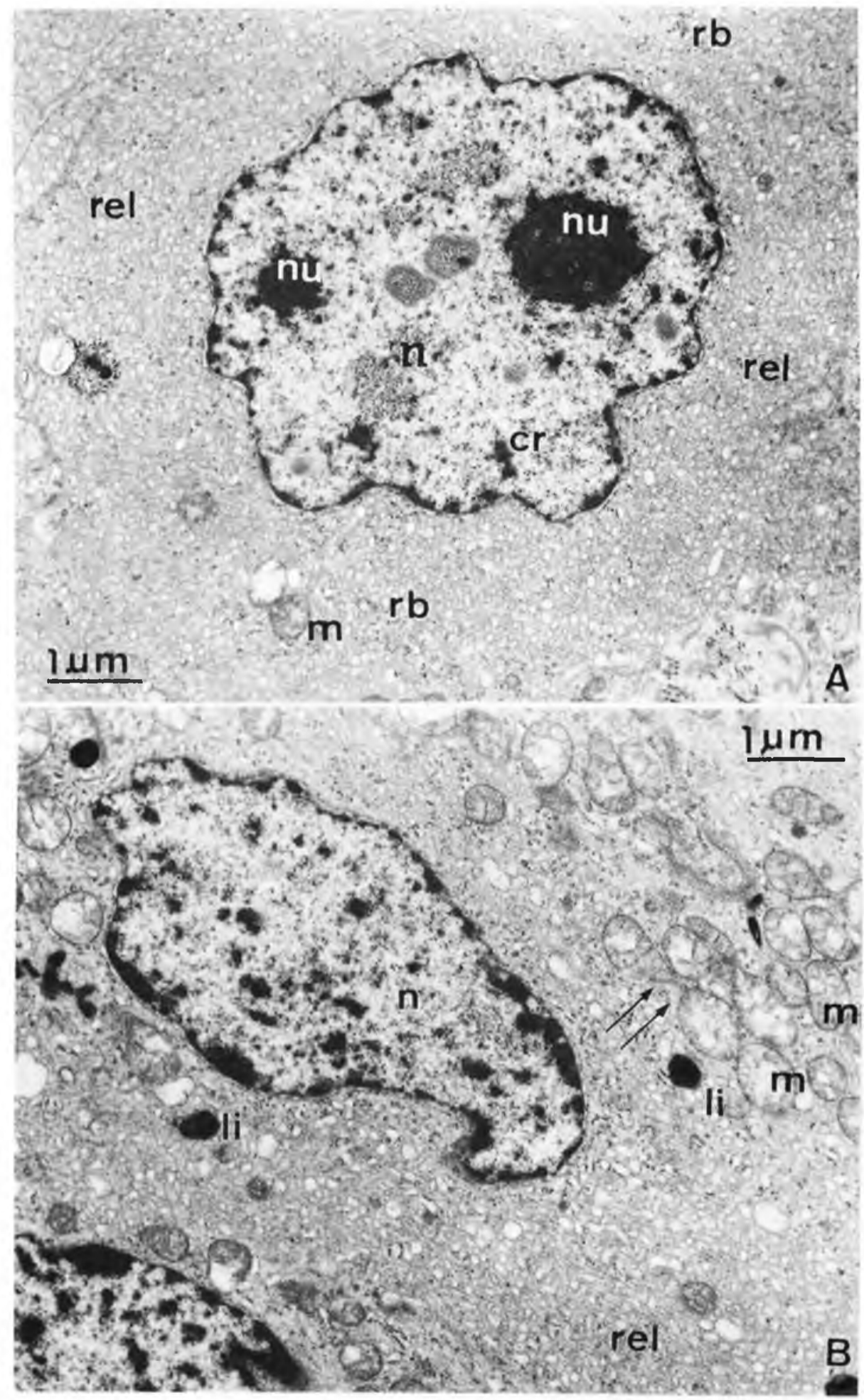

FIGURA 1 - Células de Leydig de cavalos. A) Micrografia mostrando caracteristicas do retículo endoplasmático liso (rel) e do núcleo (n). B) Aspectos das mitocóndrias (m) e lisossomos (li) em célula de Leydig. ( $\mathrm{rb}=$ ribossomos; $\mathrm{nu}=$ nucléolo; $\mathrm{cr}=$ cromatina) 


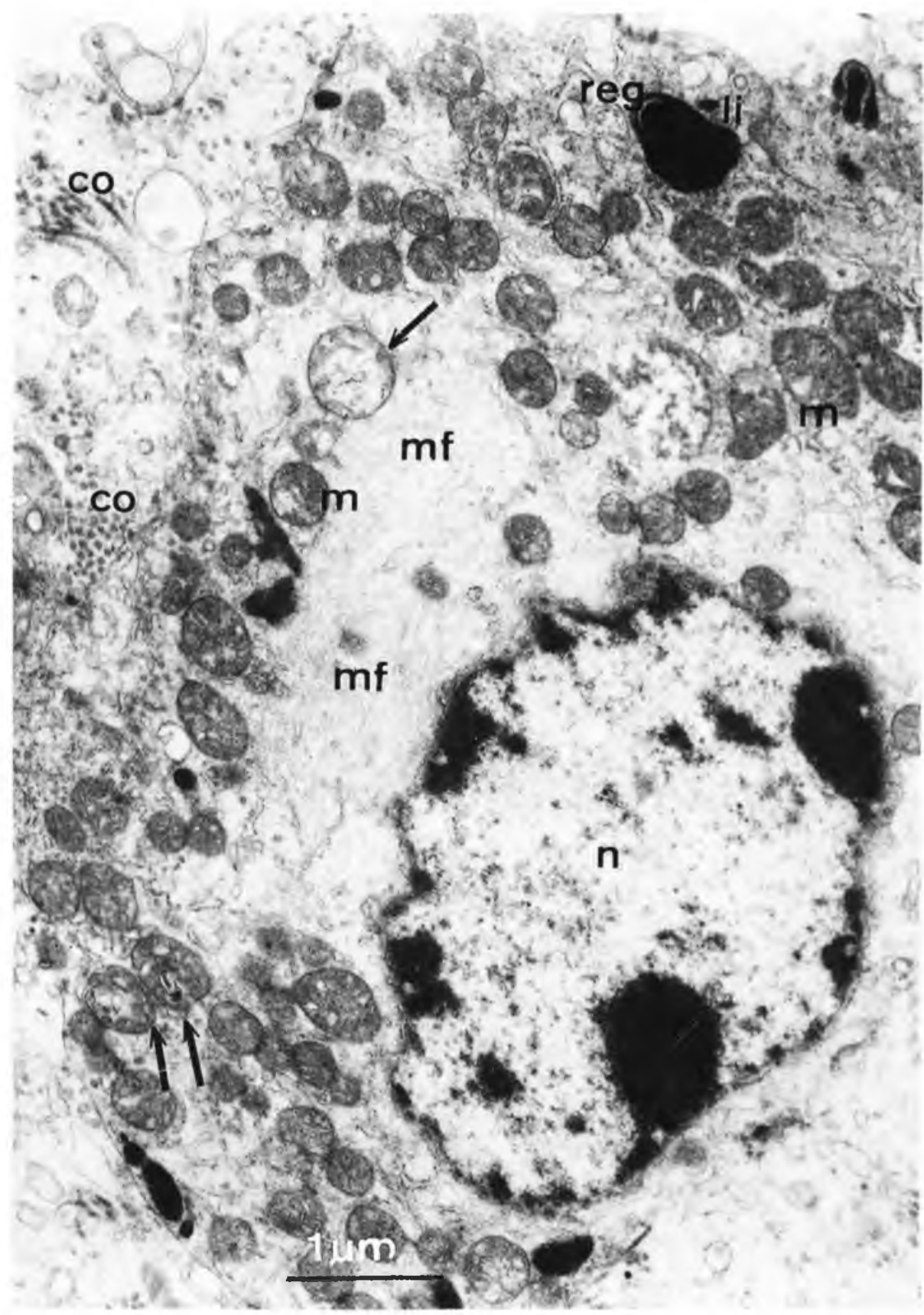

FIGURA 2 - Célula de Leydig de jumento, mostrando grande quantidade de microfilamentos (mf) ao redor do núcleo $(\mathrm{n})$. Setas indicam mitocôndrias $(\mathrm{m})$ em degeneração. (co = colágeno: reg = retículo endoplasmático rugoso; $\mathrm{li}=$ (isossomos) 